\title{
Desain Sistem Berorientasi Objek Pada Retail Minimarket Surya Mart
}

\author{
Sunardi ${ }^{1}$, Abdul Fadlil ${ }^{2}$, Tresna Yudha Prawira ${ }^{3}$ \\ Magister Teknologi Informatika, Universitas Ahmad Dahlan \\ Jl. Prof. Dr. Soepono, S.H., Warungbroto, Umbulharjo, Yogyakarta \\ sunardi@mti.uad.ac.id ${ }^{1}$, fadlil@mti.uad.ac.id ${ }^{2}$, yudhatresna21@gmail.com ${ }^{3}$
}

\begin{abstract}
The process of a minimarket retail business needs a system infrastructure so that the management process is easier to do and business processes can run more effectively. In this research, a system design process is carried out to give an overview of the business units at the Surya Mart minimarket retail, to create a system design object-oriented system analysis by making a UML diagram (unified modeling language) including making use case diagrams, activity diagrams, sequence diagram, and class diagram. From the results of the analysis, the results of this study obtain the results of a design or system design in the form of user interface design, database structure and structured query language to become a reference in the development process of the business to become a product application for the Surya Mart retail minimarket business process.
\end{abstract}

Keywords: Design, Management, System, Object Oriented

\begin{abstract}
Abstrak
Proses bisnis sebuah retail minimarket perlu adanya sebuah infrastrukur sistem agar proses manajemen lebih mudah dilakukan dan proses bisnis dapat berjalan lebih efektif. Pada penelitian ini dilakukan proses desain sistem untuk memberi gambaran terhadap unit bisnis pada retail minimarket Surya Mart, untuk menciptakan sebuah desain sistem dilakukan pola analisis sistem berorientasi objek dengan membuat sebuah diagram UML (unified modelling language) diantaranya adalah membuat use case diagram, activity diagram, sequence diagram, dan class diagram. Dari hasil analisis maka hasil penelitian ini menadapatkan hasil sebuah desain atau rancangan sistem berupa desain user interface, structure database dan structured query language untuk menjadi reverensi dalam proses development agarmenjadi sebuah product aplikasi proses bisnis retail minimarket Surya Mart.
\end{abstract}

Kata kunci: Desain, Manajemen, Sistem, Berorientasi, Objek

\section{PENDAHULUAN}

Proses bisnis perdagangan seperti retail minimarket tidak lepas dari manajemen sistem informasi untuk meningkatkan kemampuan dalam melakukan manajemen proses bisnis. Model retail minimarket yang memiliki cabang dalam mengelola seluruh proses kegiatan bisnis tentunya diperlukan peran manajemen sistem informasi, dengan data yang saling terhubung antara retail minimarket dapat dikemas dan dibuat bentuk report / laporan sehingga dapat memudahkan manajemen dan penyetok barang dalam memonitoring laporan penjualan, laba, rugi, dan penanganan stock barang. 
Pada penelitian ini akan dikaji sebuah proses bisnis yang akan diterapkan pada retail minimarket Surya Mart dengan mensimulasikan segala bentuk manajemen proses bisnis 2 (dua) retail minimarket dengan analisis sistem berorientasi objek sehingga dapat melahirkan sebuah desain sistem berorientasi objek untuk menjadi dasar rancangan proses bisnis berbasis retail minimarket di lihat dari segi infrastruktur sistem informasi. Sistem informasi merupakan cara tertentu untuk menyediakan informasi yang dibutuhkan oleh organisasi untuk beroperasi dengan cara yang sukses dan untuk organisasi bisnis dengan cara yang menguntungkan[1].

Sistem informasi manajemen sebagai sistem informasi yang digunakan untuk mendukung operasi, menyajikan informasi yang digunakan untuk mendukung operasi, manajemen, dan pengambilan keputusan dalam organisasi[2]. Analisis sistem berorientasi objek merupakan Teknik yang model-driven yang mengintegrasikan data dan proses ke dalam konstruksi yang disebut objek. Modelmodel Object Oriented Analysis (OOA) adalah gambar-gambar yang mengilustrasikan objek-objek sistem dari berbagai macam perspektif, seperti struktur, kelakun, dan interaksi objek-objek. Object Oriented Design (OOD) merupakan pendekatan yang digunakan untuk menentukan solusi perangkat lunak khususnya pada objek yang berkolaborasi[3].

UML (unified modelling language) salah satu standar bahasa yang digunakan untuk mendefinisikan requirement, membuat analisis dan desain sistem, serta menggambarkan arsitektur dalam analisis sistem berorientasi objek[3]. Jenis-jenis diagram UML yang digunakan untuk melakukan analisis sistem berorientasi objek diantaranya use case diagram, activity diagram, sequence diagram dan class diagram. Penelitian mengenai analisis dan perancangan sistem informasi penjualan berorientasi objek pada supermarket " $\mathrm{X}$ " yang dilakukan oleh Chandra setiawan komar, yang menghasilkan sebuah rancangan konsep sistem informasi dengan teknologi yang sederhana tetapi cepat dan handal[4]. Dari kajian penelitian terdahulu penulis hanya menemkan satu jurnal penelitian yang sedikit relevan, dari dasar itu juga penulis bermaksud melakukan penelitian membuat sebuah desain sistem berorientasi objek yang siap dilakukan proses development dengan study kasus proses bisnis retail minimarket Surya Mart.

\section{METODOLOGI PENELITIAN}

Metodologi penelitian menggunakan prosedur pengembangan model prototipe (prototyping model), model ini digunakan untuk menyambungkan ketidak pahaman pelanggan mengenai hal teknis dan memperjelas spesifikasi kebutuhan yang diinginkan pelanggan kepada seorang analis sistem.

Model prototipe dimulai dari pengumpulan kebutuhan pelanggan terhadap perangkat lunak yang kan dibuat, lalu dibuatlah prototipe berupa desain dari analisis sistem berorientasi objek agar pelanggan lebih terbayang dengan yang sebenarnya diinginkan. Pengembangan model prototipe akan menghasilkan sebuah mock-up, mock-up adalah sesuatu yang digunakan sebagai model desain 
yang digunakan untuk mengajar, demonstrasi, evaluasi desain, promosi, atau keperluan lain.

\subsection{Kerangka Pemikiran}

Kerangka pemikiran merupakan alur pikir peneliti yang dijadikan sebagai sekema pemkiran atau dasar-dasar pemikiran untuk memperkuat indicator yang melatar belakangi penelitian ini. Dalam kerangka pemikiran penelitian ini peneliti menjelaskan alur masalah pokok penelitian. Alur yang disusun menggambarkan permasalahan yang akan diseleseikan.

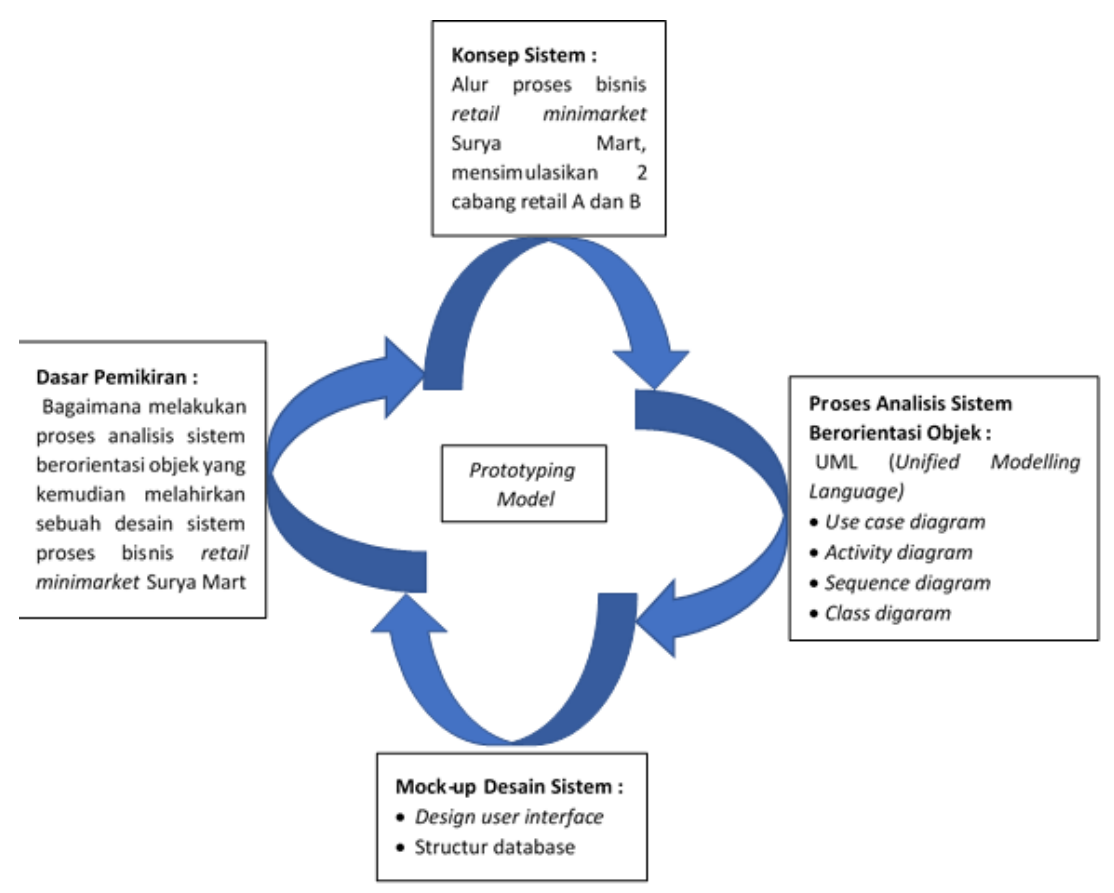

Gambar 1. Kerangka pemikiran penelitian.

\subsection{Konsep Sistem}

Konsep sistem adalah melakukan Analisa alur sistem dan kebutuhan sistem sehingga menghasilkan sebuah konsep sistem proses bisnis retail minimarket Surya Mart.

\subsection{Proses Analisis Sistem}

Analisis sistem berorientasi objek menggunakan alat bantu/tool yaitu IBM Rational Rose untuk membuat diagram UML (Unified Modelling Language) berupa use cae diagram, activity diagram, sequence diagram, dan class diagram.

\subsection{Mock-up Desain Sistem}

Dari proses analisis sistem berorientasi objek tahap analisis sequence diagram dapat menghasilkan sebuah design user interface, dan class diagram 
memiliki fungsi sama seperti ERD (Entitty Rrelationship Diagram) yaitu untuk melakukan pemodelan data sehingga dapat melahirkan sebuah structure database.

\section{HASIL DAN PEMBAHASAN}

\subsection{Konsep Sistem}

Tahap konsep sistem menggambarkan tentang sekumpulan elemen-elemen yang saling berkaitan dan saling mempengaruhi dalam kegiatan proses bisnis pada organisai retail minimarket Surya Mart. Konsep sistem akan menggambarkan sebuah supersystem yaitu gambaran dari alur sistem secara umum dan kemudian didalam supersystem terdapat subsistem yang menggambarkan proses aktivitas pada unit kerja pada proses bisnis retail minimarket Surya Mart.

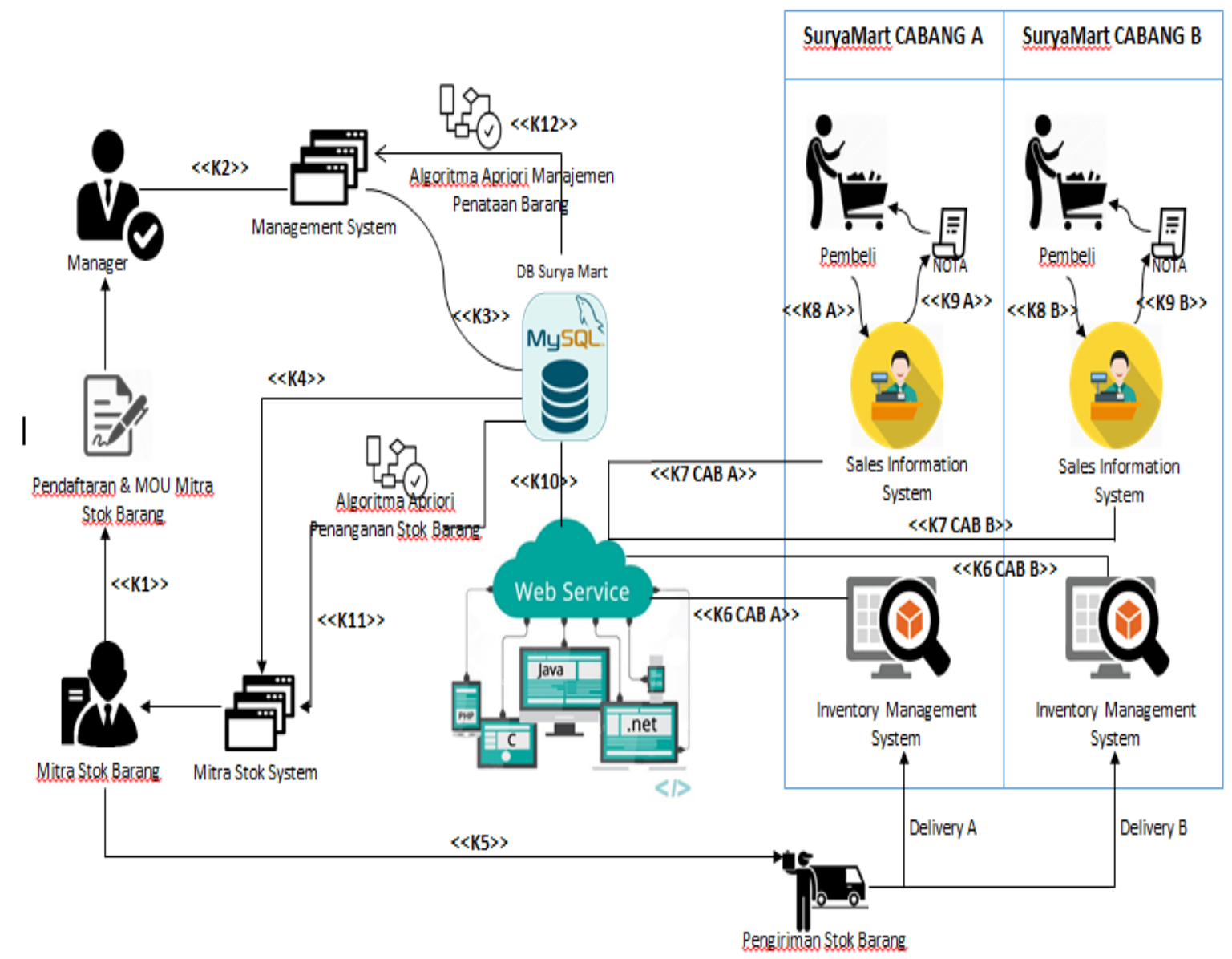

Gambar 2. Konsep Sistem Proses Bisnis Retail Minimarket Surya Mart.

Gambar 2 adalah alur supersystem pada konsep proses bisnis retail Surya Mart, setiap garis yang ada menggambarkan alur komunikasi pada masing-masing subsistem. Subsistem dalam hal ini adalh unit kerja yang ada pada retail minimarket Surya Mart yaitu: 1.Subsistem management system, 2.Subsistem inventory management sstem, 3.Subsistem sales information system, 4.Subsistem mitra stok system. 


\subsection{Analisis Sistem Berorientasi Objek}

Setelah unit kerja/subsistem teridentifikasi berkutnya adalah melakukan proses analisis dengan membuat diagram UML (Unified Modelling Language) dengan membuat use case diagram, activity diagram, sequence diagram, dan class diagram. Sebagai contoh proses analisis berupa use case diagram pada unit kerja/subsistem :

a. Use case diagram management system

Menggambarkan sebuah alur sistem bagaimana seorang manager melakukan proses management pegawai, penempatan, bagian dan mitra stok sebagai penyetok barang.

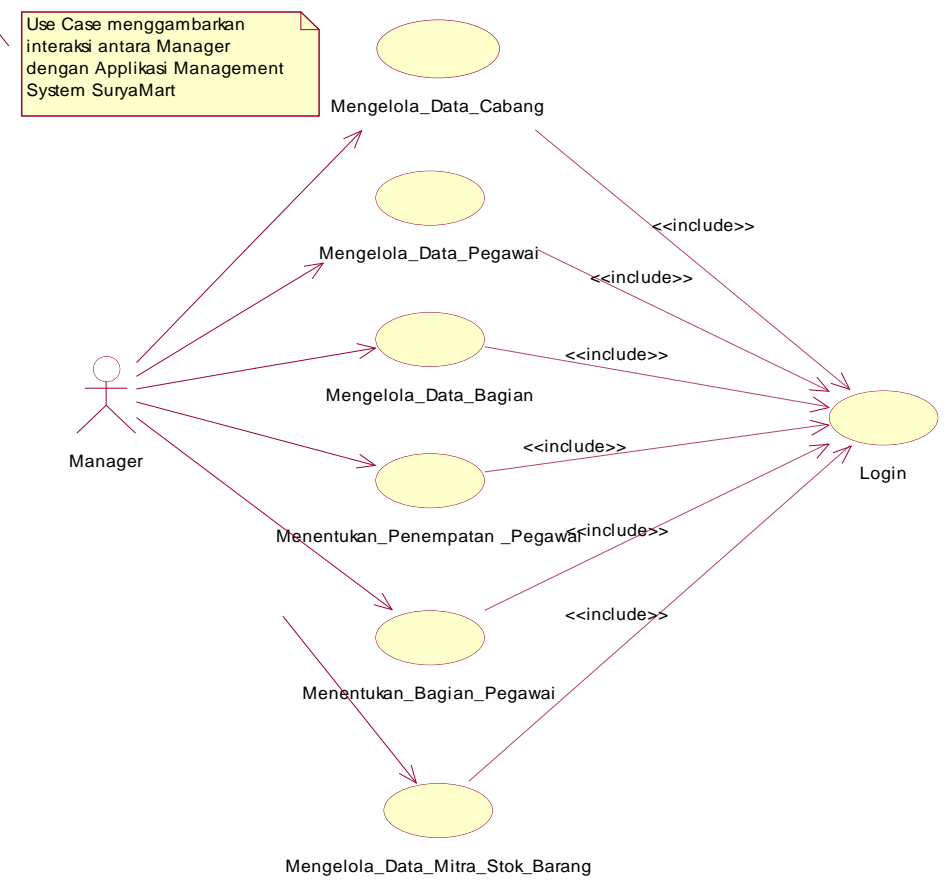

Gambar 3. Use case diagram management system

b. Use case diagram inventory management system

Menggambarkan sebuah alur pengelola gudang dalam melakukan proses transaksi penerimaan barang yang dilakukan oleh mitra penyetok barang. 
Jurnal Riset Sistem Informasi Dan Teknik Informatika (JURASIK)

Volume (4) Juli 2019, pp 55-64

ISSN: 2527-5771/EISSN: 2549-7839

http://tunasbangsa.ac.id/ejurnal/index.php/jurasik

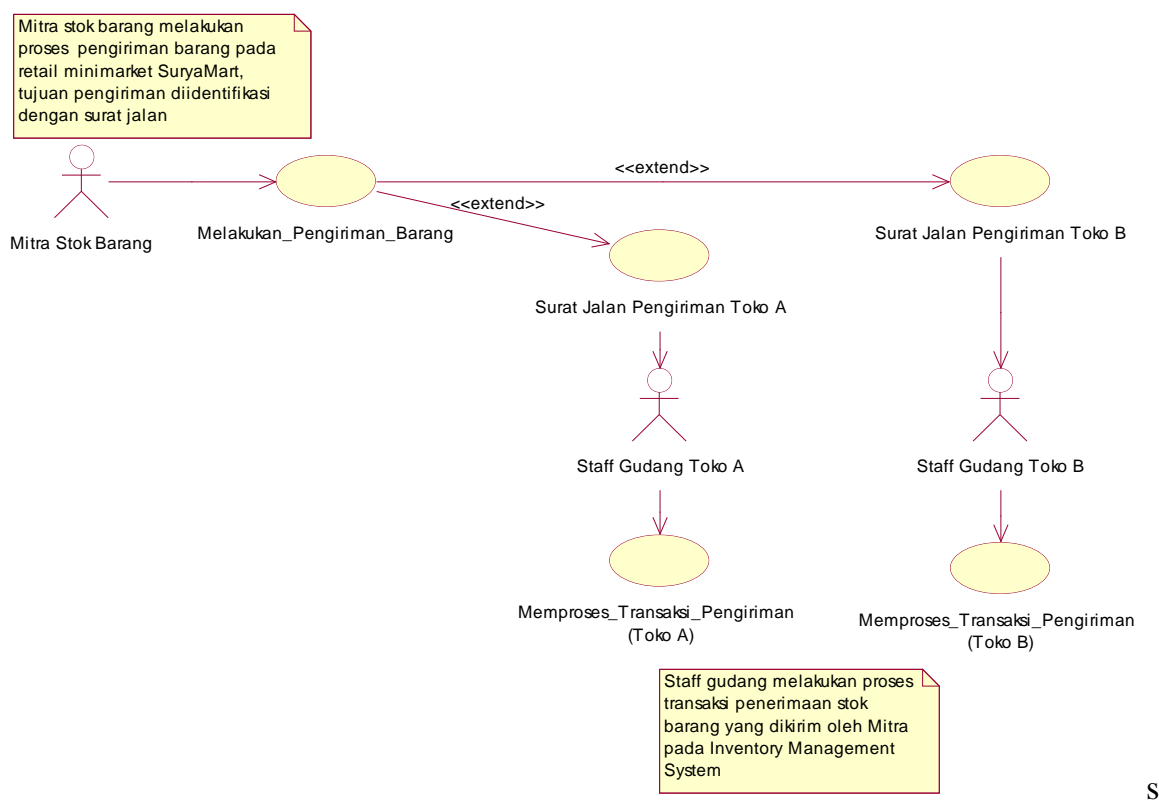

Gambar 4. Use case diagram inventory management system

c. Use case diagram sales information system

Sales information system adalah subsistem yang menangani proses transaksi penjualan pada tiap cabang retail minimarket.

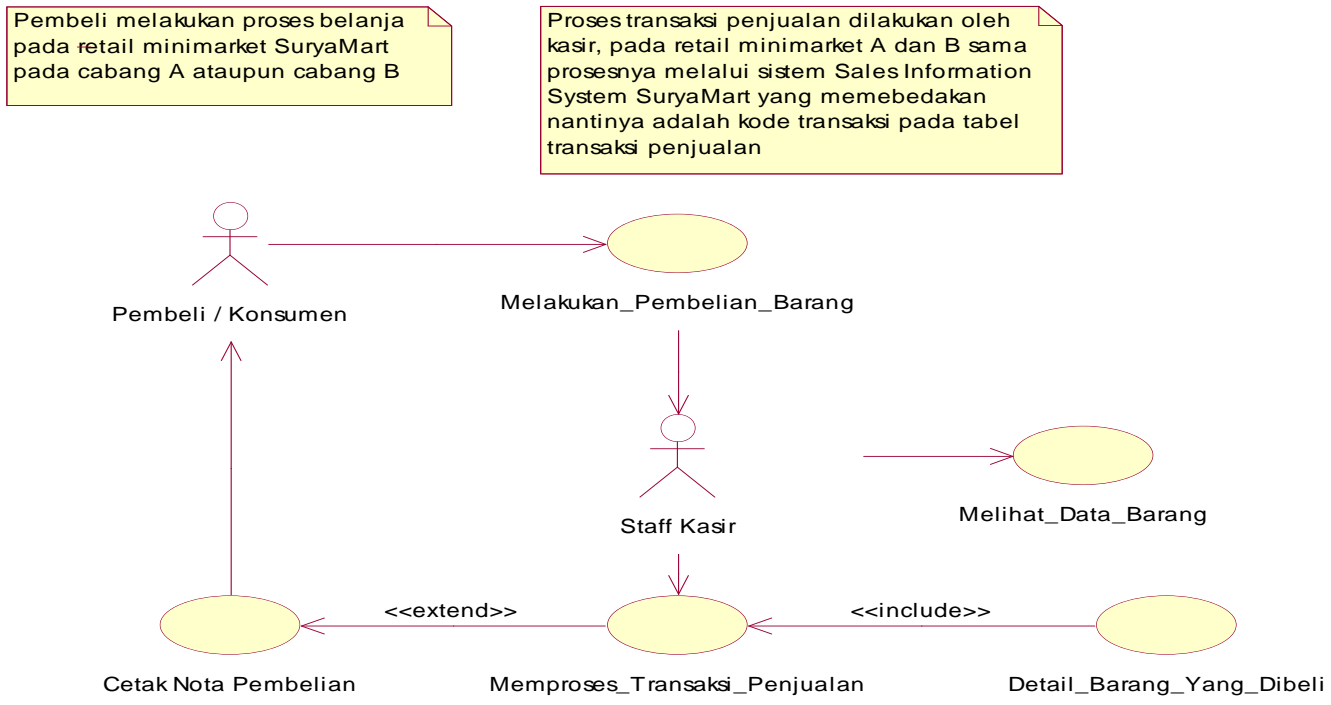

Gambar 5. Use Case diagram sales information system

d. Use case diagram mitra stok system

Mitra stok system sebuah sistem yang menjembatani penyetok barang/supplier terhadap setiap cabang retail minimarket Surya Mart, melalui sistem ini penyetok barang dapat melakukan monitaoring barang yang distok-nya pada retail Surya Mart. 


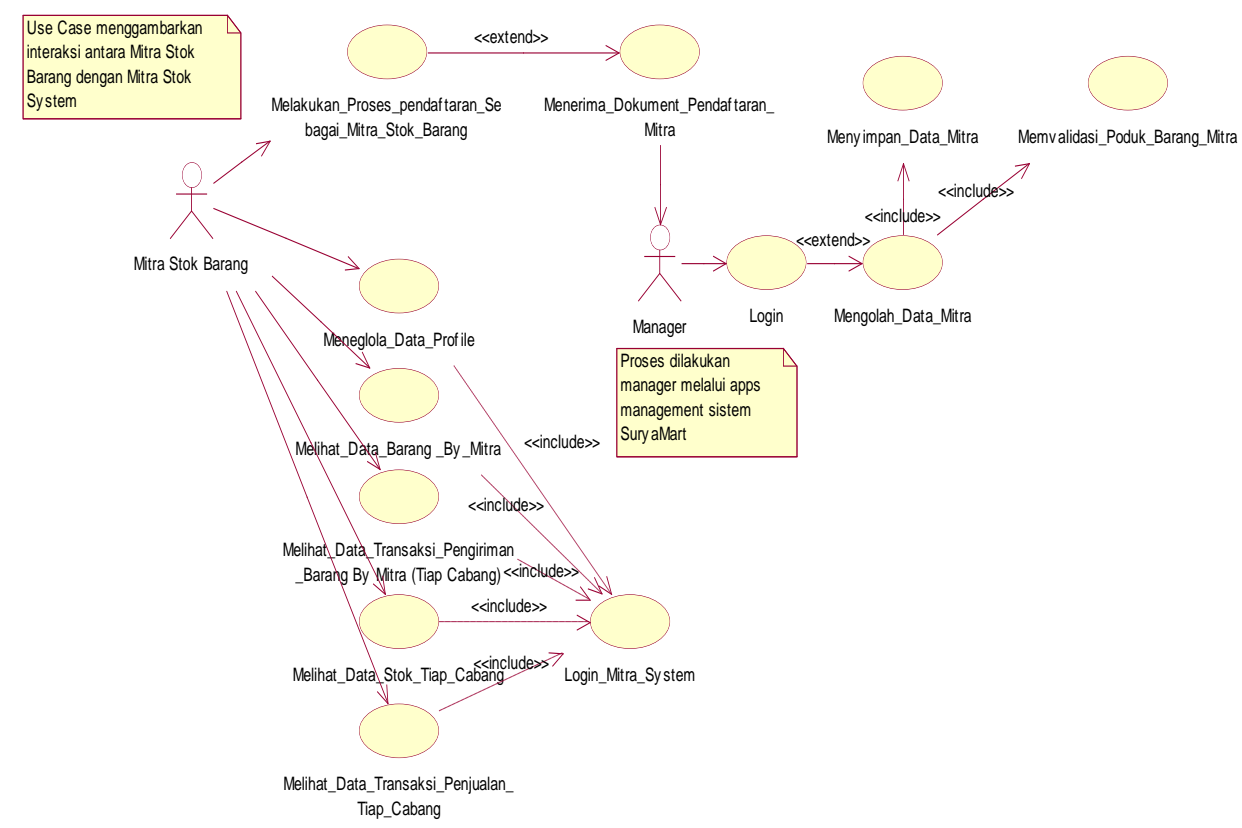

Gambar 6. Use case diagram mitra stok system

\subsection{Mock-up Desain Sistem}

Dari hasil analisis sistem yang dilakukan dalam penelitian ini dengan melakukan tahap pembuatan use case, activity, sequence, dan class diagram maka diagram dari analisis sistem berorientasi objek dapat menjadi referensi untuk menghasilkan sebuah desain sistem, desain sistem inilah yang dimaksud dengan sbuah mock-up untuk menjadi acuan kerja proses development yang dilakukan oleh designer user interface dan programmer.

\section{a. Desain user interface}

Desain user interface mengambil dari analisis sequence diagram untuk menjadi sebuah rancangan GUI graphical user interface dari aplikasi pada unit kerja yang ada pada retail minimarket Surya Mart.

1) Halaman utama management system

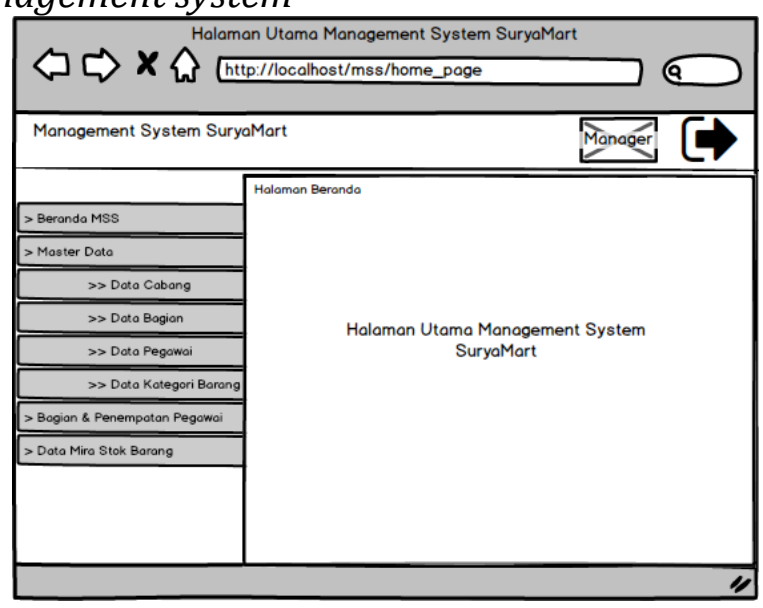


Jurnal Riset Sistem Informasi Dan Teknik Informatika (JURASIK)

Volume (4) Juli 2019, pp 55-64

ISSN: 2527-5771/EISSN: 2549-7839

http://tunasbangsa.ac.id/ejurnal/index.php/jurasik

Gambar 7. Halaman utama inventory management system

2) Halaman utama inventory management system

\begin{tabular}{|c|c|c|c|}
\hline \multicolumn{3}{|c|}{ Halaman Utama Inventory Management System } & \multirow{3}{*}{-[]$x$} \\
\hline \multicolumn{2}{|c|}{ Transaksi Penerimaan } & Master Dato & \\
\hline Exit & & $\begin{array}{l}\text { Data Barang Dan Jumlah Stok } \\
\text { Dato Transaksi Penerimaan }\end{array}$ & \\
\hline \multicolumn{4}{|c|}{$\begin{array}{l}\text { Halaman Utama } \\
\text { Inventory Managemen System SuryaMart }\end{array}$} \\
\hline \multirow{2}{*}{$\begin{array}{l}\text { Session Cabang } \\
\text { Session Pegawai }\end{array}$} & SuryaMart A & Hilden (Volve=IDCobong) & \\
\hline & Nama Pegawai & Hilden (Value=IDPegawai) & \\
\hline
\end{tabular}

Gambar 8. Halaman utama inventory management system

3) Halaman utama sales information system

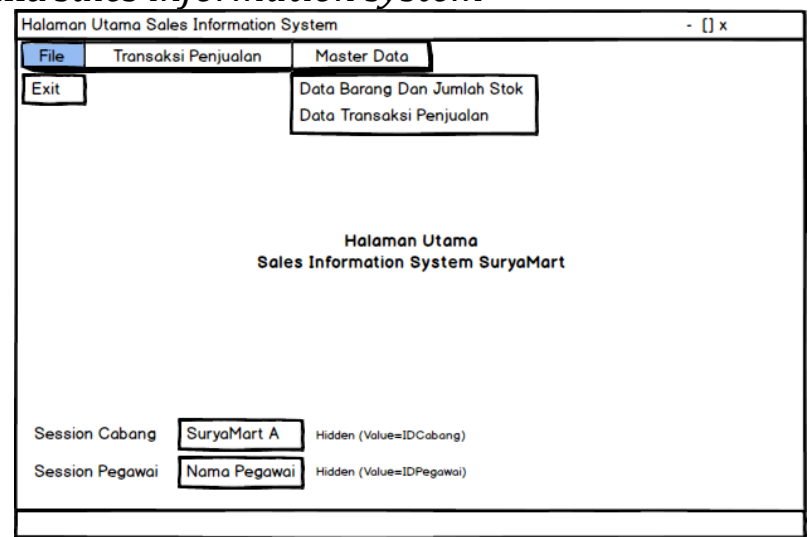

Gambar 9. Halaman utama sales information system

4) Halaman mitra stok system

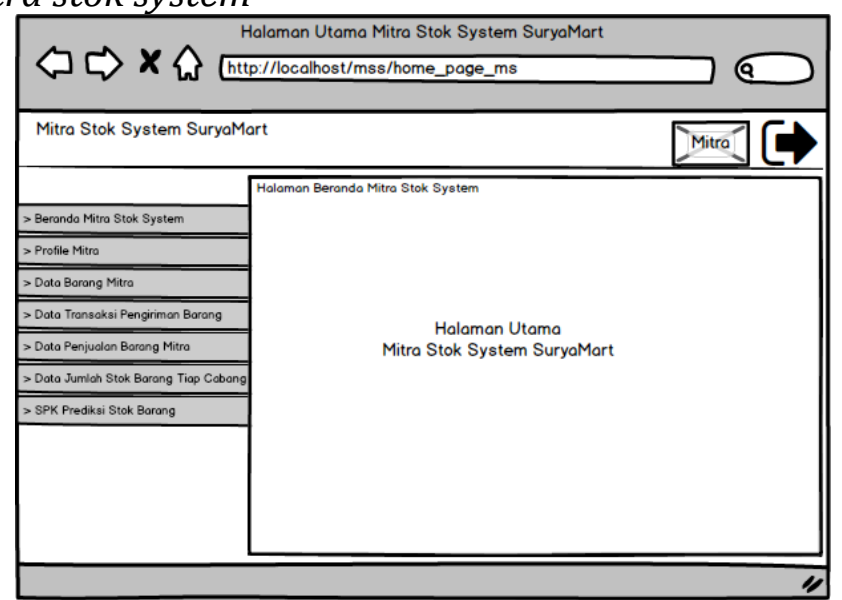

Gambar 10. Haaman utama mitra stok system 
5) Structur Database

Hasil analisis class diagram memiliki fungsi yang sama dengan konsep ERD (entity relationship diagram) yang dapat menghasilkan struktur kebutuhan dari database.

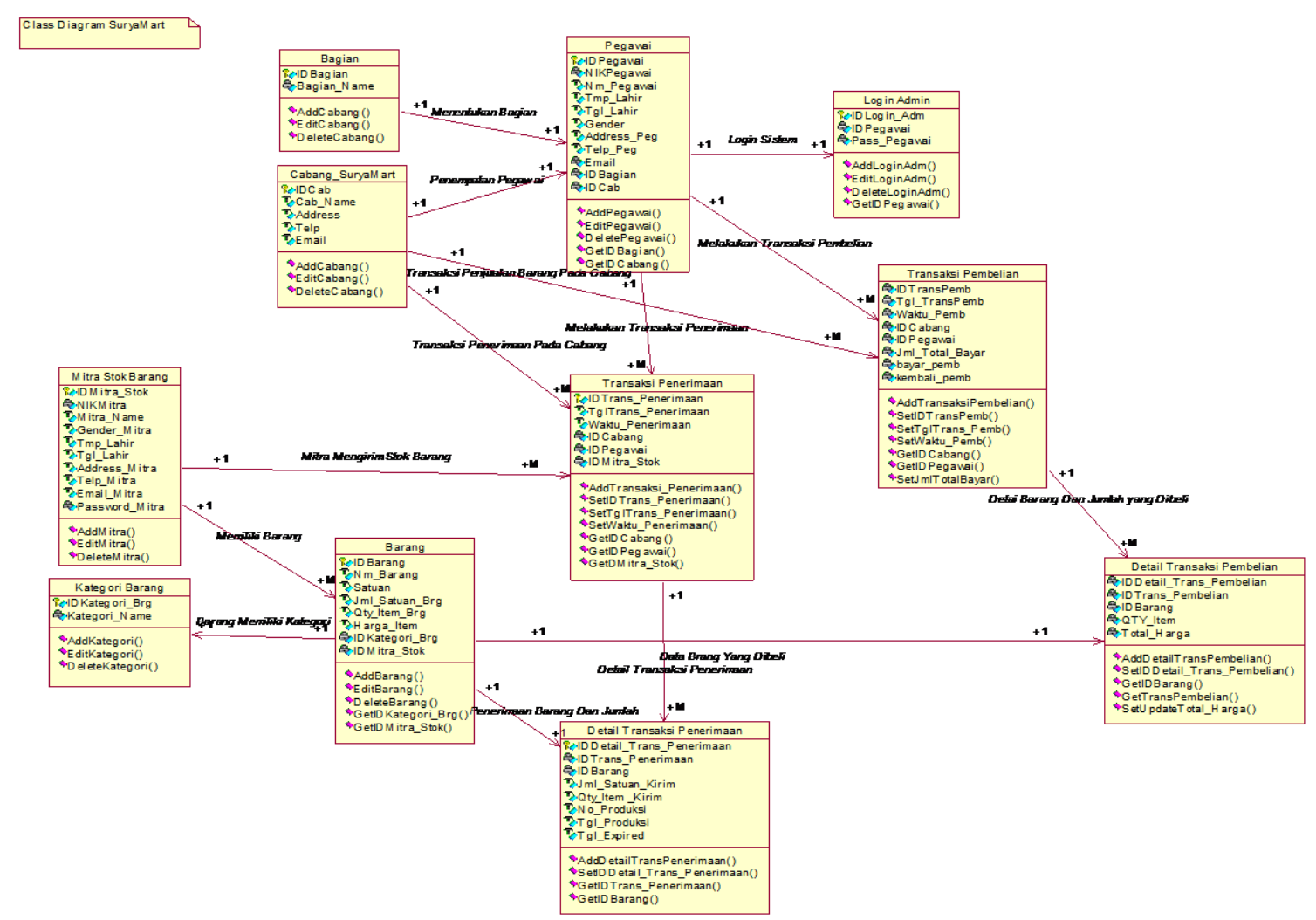

Gambar 11. Class diagram proses bisnis secara umum.

Dari structure database relation pada Gambar 11 kemudian dapat dilakukan proses implementasi pada $M y S Q L$ tool dan kemudian dilakukan simulasi pengujian alur data dengan SQL Query (structure query language) dengan output data menyeseuaikan dengan tabel yang ada pada design user interface untuk memastikan bahwa hasil analisis sistem berorientasi objek pada retail minimarket Surya Mart apakah dapat berkerja secara efektif dari segi alur komunikasi data pada tiap-tiap tabel yang ada dalam database yang sudah dirancang untuk proses bisnis retail Surya Mart.

\section{SIMPULAN}

Dari hasil penelitian yang telah dilakukan, maka dapat diambil kesimpulan sebagai berikut:

a) Proses bisnis berupa retail minimarket yang memiliki cabang dibutuhkan sistem dengan data yang saling terintegrasi agar manajemen pengelolaan menjadi 
mudah, dalam penelitian ini menghasilkan sebuah konsep integrasi sistem dengan teknologi web service.

b) Pada penelitian ini menghasilkan konsep supersystem dimana di dalamnya terdapat subsistem sebagai unit kerja yang ada dalam organisasi retail minimarket Surya Mart. Subsistem yang kemudian dianalisis dengan pendekatan berorientasi objek diantaranya adalah :

1. Management system berfungsi untuk melakukan management data tiap cabang, karyawan, hingga penyetok barang.

2. Mitra stock system merupakan sistem untuk melakukan proses interaktif antar penyetok barang/supplier terhadap barang yang distoknya.

3. Inventory management system merupakan sistem yang melakukan proses penerimaan barang dan pengelola barang pada gudang setiap retail minimarket Surya Mart.

4. Sales information system merupakan sistem yang digunakan kasir dalam penanganan penjualan barang.

5. Pembuatan diagram UML (unified modelling language) melalui use case diagram, activity diagram, sequence diagram, dan class diagram pada konsep sistem retail minimarket Surya Mart dapat menjadi referensi untuk dijadikan sebuah desain rancangan sistem. Preferensi dari sequence diagram dapat melahirkan design user interface dan class diagram dapat melahirkan struktur database untuk proses bisnis Surya Mart.

6. Struktur database yang dibentuk dari class diagram dapat diimplementasikan ke dalam daabase MySQL dan kemudian dilakukan uji coba dengan referensi output data diambil dari design user interface dan dari proses pengujian dapat melahirkan sebuah structure query language.

7. Design user interface, structure database, dan structure query language dapat dijadikan desain sistem yang siap dilakukan proses development menjadi sebuah project aplikasi proses bisnis retail minimarket Surya Mart.

\section{DAFTAR PUSTAKA}

[1] Wahyono, Teguh. Sistem Informasi, Konsep Dasar, Analisa Desain dan Implementasi. Yogyakarta : Graha Ilmu. 2004.

[2] Abdul Kadir. Pengenalan Sistem Informasi. Andi. Yogyakarta. 2002.

[3] R. A. Sukamto dan M. Shalahuddin, Rekayasa Perangkat Lunak, Bandung: Informatika, 2013.

[4] Chandra Setiawan Komar. 2005. "Analisis dan Perancangan Sistem Informasi Penjualan Berorientasi Objek Pada Supermarket X", Media Informatika, 4(1) : 33 - 42.

[5] Davis B. Gordon, (1985), Kerangka Dasar, Sistem Informasi Manajemen, Seri manajemen No. 90-A: PT Pustaka Binaman Pressindo.

[6] Hanif Al Fatta. 2007. Analisis dan Perancangan Sistem Informasi. Andi. Yogyakarta.

[7] Hartono, Bambang. 2013. Sistem Informasi Manajemen Berbasis Komputer. Jakarta: Rineka Cipta

[8] Jogiyanto, H. M, (1999), Analisis dan Desain Sistem Informasi, Yogyakarta: Andi.

[9] Pressman,Ph.D. Roger S. 2010. Pendekatan Praktisi Rekayasa Perangkat Lunak. Edisi 7. Penerbit Andi. Yogyakarta.

[10]Robert G. Murdick.1993. Sistem Informasi Untuk Manajemen Modern Edisi 3. Erlangga. Jakarta 